\title{
Significance of fractional exhaled nitric oxide in chronic eosinophilic pneumonia: a retrospective cohort study
}

\author{
Ji Young Park ${ }^{1,2}$, Taehoon Lee ${ }^{1,2}$, Hongyeul Lee ${ }^{1,2}$, Yeon Joo Lee ${ }^{1,2}$, Jong Sun Park ${ }^{1,2}$, Young-Jae Cho ${ }^{1,2}$,
} Ho $\|$ Yoon ${ }^{1,2}$, Jae Ho Lee ${ }^{1,2}$ and Choon-Taek Lee ${ }^{1,2^{*}}$

\begin{abstract}
Background: Chronic eosinophilic pneumonia (CEP) is characterized by chronic eosinophilic infiltration of the lung. It is dramatically responsive to corticosteroid treatment, but symptoms and radiopacities recur frequently after tapering or discontinuing the medication. Fractional exhaled nitric oxide (FeNO) is a well-known noninvasive marker of eosinophilic airway inflammation. The aim of this retrospective cohort study was to investigate the relationships of FeNO with peripheral eosinophilia and the clinical state of CEP and its validity for predicting exacerbation of CEP.

Methods: Standard clinical and laboratory parameters, peripheral eosinophil percentage and count, and FeNO level were measured in 18 patients with CEP at several assessment points over 1 year.

Results: FeNO level was positively correlated with peripheral eosinophil count $(r=0.341, P=0.005)$ and percentage $(r=0.362, P=0.003)$. The median (IQR) FeNO levels were $79(41-88)$ and 35 (26-49) ppb in uncontrolled (13/74 measurements) and controlled (61/74 measurements) CEP, respectively $(P=0.010)$. The FeNO level of $66.0 \mathrm{ppb}$ showed the largest area under the curve (0.835) for predicting exacerbation of CEP (sensitivity $=0.80$, specificity $=0.84$ ).

Conclusion: FeNO may be useful for monitoring eosinophilic parenchymal inflammation and determining the appropriate corticosteroid dose in CEP.
\end{abstract}

Keywords: Chronic eosinophilic pneumonia, Fractional exhaled nitric oxide, Biomarker, Corticosteroid

\section{Background}

Chronic eosinophilic pneumonia (CEP) is a rare disease of unknown cause. It is characterized by chronic respiratory symptoms, bilateral peripheral lung opacities, pulmonary eosinophilia, and/or peripheral eosinophilia. CEP shows a dramatic response to corticosteroids. Symptoms and radiopacities resolve rapidly after corticosteroid treatment [1], but they recur frequently after tapering or discontinuing the medication [1,2]. Most patients need prolonged tailored treatment, similar to those with asthma

\footnotetext{
* Correspondence: ctlee@snu.ac.kr

'Division of Pulmonary and Critical Care Medicine, Department of Internal Medicine and Respiratory Center, Seoul National University Bundang Hospital, 173-82 Gumi-Ro, Bundang-Gu, Seongnam 463-707, Republic of Korea

${ }^{2}$ Division of Pulmonary and Critical Care Medicine, Department of Internal Medicine, Seoul National University College of Medicine, Seoul, Republic of
} Korea

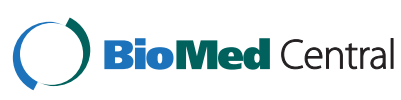

(c) 2014 Park et al.; licensee BioMed Central Ltd. This is an Open Access article distributed under the terms of the Creative Commons Attribution License (http://creativecommons.org/licenses/by/4.0), which permits unrestricted use, distribution, and reproduction in any medium, provided the original work is properly credited. The Creative Commons Public Domain Dedication waiver (http://creativecommons.org/publicdomain/zero/1.0/) applies to the data made available in this article unless otherwise stated.
[3]. Therefore, a marker is required to assist in monitoring and controlling CEP.

FeNO is an important marker of eosinophilic airway inflammation in diseases such as asthma and nonasthmatic eosinophilic bronchitis [4]. In asthma, FeNO level is significantly correlated with eosinophil counts in bronchoalveolar lavage (BAL) fluid, induced sputum, and airway mucosal tissue [5-7]. It can identify patients with asthma who are likely to benefit from corticosteroid treatment and have reduced exacerbation rates [8-10]. Transition of asthma from the well-controlled to the poorly controlled state is associated with a rise in FeNO level [11]. Further, maintenance doses of inhaled corticosteroids can be reduced without loss of asthma control on the basis of FeNO level $[12,13]$. However, its value in eosinophilic parenchymal lung disease is unknown because inducible

res othersise stated. 
nitric oxide synthetase, the major source of FeNO, is usually found in airway epithelium [14].

Recently, our group reported that FeNO level is significantly higher in patients with acute eosinophilic pneumonia (AEP) than in those without AEP and decreases during corticosteroid treatment, strongly suggesting that FeNO level increases in eosinophilic parenchymal lung diseases [15]. Further, FeNO level is lower in patients with stable bronchiectasis than in those with asthma or chronic obstructive lung disease, implying that FeNO has no role in neutrophilic airway inflammation [16]. In this study, we explored the significance of FeNO in the diagnosis and management of CEP, an eosinophilic lung parenchymal disease, by investigating its relationships with peripheral eosinophilia and the clinical state of CEP and its validity for predicting exacerbation of CEP.

\section{Methods}

\section{Study design and definitions}

This retrospective cohort study was conducted at Seoul National University Bundang Hospital between November 2011 and October 2012. The Institutional Review Board approved the study protocol and waived the need for informed consent from patients (B-1210-174-105).

Diagnosis of CEP was based on the following criteria: (i) pulmonary opacities with peripheral predominance on chest radiography; (ii) peripheral eosinophilia $\geq 1000$ cells/ $\mu \mathrm{L}$ and/or alveolar eosinophilia $\geq 40 \%$ of the eosinophil count in BAL fluid; (iii) respiratory symptoms for over 2 weeks; and (iv) exclusion of known causes of eosinophilic pneumonia (parasitic infection, drugs, or allergic bronchopulmonary aspergillosis), eosinophilic granulomatosis with polyangiitis (Churg-Strauss syndrome), and hypereosinophilic syndrome [1].

Exacerbation was defined as reappearance of characteristic infiltrates on chest radiography, recurrence of typical clinical features, and increasing peripheral eosinophilia. Uncontrolled CEP was defined as administration or increasing dosage of corticosteroids due to diagnosis or exacerbation of CEP. Controlled CEP was defined as absence of symptoms regardless of corticosteroid dose.

\section{Measurements}

At each visit during the 1-year study period, we assessed symptoms, chest radiographic findings, peripheral eosinophil count and percentage, and FeNO level. The recall interval was individualized according to the clinical state: most patients were reexamined every $2-3$ months, but some patients with uncontrolled CEP were recalled before the scheduled appointment. Change in FeNO levels between visits was calculated at every assessment point, as follows: $\Delta \mathrm{FeNO}=\mathrm{FeNO}_{n}-\mathrm{FeNO}_{n-1}$, where $n$ and $n-1$ represent the $n$-th and preceding visits, respectively. Changes in peripheral eosinophil count ( $\Delta$ eosinophil count) and percentage ( $\Delta$ eosinophil percentage $)$ were similarly calculated.

FeNO level was measured by using a NIOX MINO monitor (Aerocrine AB, Solna, Sweden), without the nose clip, at an exhalation flow rate of $50 \mathrm{~mL} / \mathrm{s}$, according to the American Thoracic Society (ATS)/European Respiratory Society (ERS) recommendation [17]. A FeNO

Table 1 Baseline characteristics of the 18 patients with CEP at diagnosis

\begin{tabular}{|c|c|c|}
\hline Variable & Value* & $\begin{array}{c}\text { Number } \\
\text { reported/tested }\end{array}$ \\
\hline Age (years) & $56(41-68)$ & 18 \\
\hline Disease duration (months) & $19.1(9.9-28.7)$ & 18 \\
\hline Gender & & 18 \\
\hline Female & $8(44.4)$ & \\
\hline Male & $10(55.6)$ & \\
\hline Smoking status & & 18 \\
\hline Current smoker & $1(5.6)$ & \\
\hline Ex-smoker & $4(22.2)$ & \\
\hline Pack-year history & $25(20-40)$ & \\
\hline Symptoms or signs & & 18 \\
\hline Cough & $15(83.3)$ & \\
\hline Sputum & $13(72.2)$ & \\
\hline Dyspnea & $5(27.8)$ & \\
\hline Fever & $2(11.1)$ & \\
\hline Wheezing & $4(22.2)$ & \\
\hline Crackle & $3(16.7)$ & \\
\hline History of tuberculosis & $1(5.6)$ & 18 \\
\hline \multicolumn{3}{|l|}{ Laboratory findings } \\
\hline 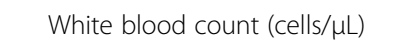 & $8060(7470-9660)$ & 18 \\
\hline $\begin{array}{l}\text { Peripheral eosinophil } \\
\text { percentage }(\%)\end{array}$ & $21.2(11.6-42.3)$ & 18 \\
\hline $\begin{array}{l}\text { Peripheral eosinophil count } \\
\text { (cells/ML) }\end{array}$ & $1543(771-4034)$ & 18 \\
\hline $\begin{array}{l}\text { Eosinophil percentage in } \\
\text { BAL fluid (\%) }\end{array}$ & $47(15-65)$ & 7 \\
\hline C-reactive protein (mg/dL) & $1.5(0.30-3.27)$ & 15 \\
\hline $\begin{array}{l}\text { Aspartate aminotransferase } \\
(\mathrm{IU} / \mathrm{L})\end{array}$ & $21(17-24)$ & 17 \\
\hline Alanine aminotransferase (IU/L) & $17(12-24)$ & 17 \\
\hline Blood urea nitrogen (mg/dL) & $10(8-11)$ & 17 \\
\hline Creatinine (mg/dL) & $0.84(0.66-0.98)$ & 17 \\
\hline \multicolumn{3}{|l|}{ Spirometric results } \\
\hline $\begin{array}{l}\text { Forced expiratory volume in } 1 \\
\text { s/forced vital capacity ratio }\end{array}$ & $76.0(62-82)$ & 15 \\
\hline $\begin{array}{l}\% \text { predicted forced expiratory } \\
\text { volume in } 1 \mathrm{~s}\end{array}$ & $87.0(67-100)$ & 15 \\
\hline $\begin{array}{l}\% \text { predicted forced vital } \\
\text { capacity }\end{array}$ & $86.0(72-97)$ & 15 \\
\hline
\end{tabular}

*Data represent median (IQR) or number of patients (\%). 
level $>50 \mathrm{ppb}$ was considered indicative of eosinophilic inflammation and responsiveness to corticosteroids in symptomatic patients and an increase over $10 \mathrm{ppb}$ suggested a significant $\triangle \mathrm{FeNO}$ value [13].

\section{Treatment}

The parameters except FeNO level were used to tailor the corticosteroid treatment. The initial regimen for patients with newly diagnosed or uncontrolled CEP was $0.5 \mathrm{mg} / \mathrm{kg} /$ day of prednisolone. The dose was gradually tapered according to the clinical state. Patients with controlled CEP generally received a maintenance dose of 2.5- to 5-mg prednisolone daily. If no exacerbation event occurred during 3 months of maintenance treatment, the medication was discontinued. If symptom aggravation, reappearance of radiopacities, and peripheral eosinophilia were noted, suggestive of uncontrolled CEP, the dosage was increased up to $0.5 \mathrm{mg} / \mathrm{kg} /$ day.

\section{Statistical analysis}

Data are presented as median (interquartile range [IQR]) values or number (\%) of patients. FeNO levels and peripheral eosinophil counts or percentages were analyzed with Pearson correlation analysis. Continuous variables were analyzed by using the Mann-Whitney $U$-test. The Wilcoxon signed-rank test was used to evaluate parametric differences during an exacerbation event and after corticosteroid administration. Receiver operating characteristic (ROC) curve analysis was used to determine the parametric values that best predicted exacerbation of CEP. $P<0.05$ was considered to be statistically significant. All analyses were performed by using SPSS for Windows (version 18.0, SPSS, Inc., Chicago, IL, USA).

\section{Results}

\section{Baseline characteristics}

Eighteen patients (10 men) were enrolled in the study; fifteen patients had been diagnosed before the study began. The median age was 56 (41-68) years (Table 1).
One patient (5.6\%) was a current smoker, and 17 patients (94.4\%) had never smoked or had stopped smoking. The most common symptom was cough $(n=15)$, followed by sputum production $(n=13)$. One patient $(5.6 \%)$ had a history of pulmonary tuberculosis. The median peripheral eosinophil percentage was $21.2 \%$ (11.6-42.3\%) of the total leukocyte count and median peripheral eosinophil count was 1543 (771-4034) cells/ $\mu \mathrm{L}$. Seven patients underwent BAL for diagnosis of CEP. The median eosinophil percentage in BAL fluid was 47\% (15-65\%).

\section{Clinical course}

Seven patients (38.9\%) had controlled CEP throughout the study. Ten exacerbation events occurred in nine patients (50\%), with one patient experiencing two episodes. In total, 74 FeNO measurements were obtained from the 18 patients, including 10 measurements during exacerbation events and three at diagnosis. Therefore, 13 FeNO measurements were obtained during uncontrolled CEP (Figure 1). Median time interval between patient visits was 56 days (IQR 28-77). Median number of visits that were attended by the patients was 4 (IQR 4-5).

\section{Relationship of FeNO and peripheral eosinophilia}

The median FeNO value, peripheral eosinophil percentage, and peripheral eosinophil count were 37 (11-165) ppb, 5.1\% (0.0-32.7\%), and $283(0-1938)$ cell $/ \mu \mathrm{L}$, respectively. FeNO level was positively but weakly correlated with peripheral eosinophil percentage $(r=0.362, P=0.003)$ and count $(r=0.341, P=0.005)$. $\Delta$ FeNO was positively and moderately correlated with $\Delta$ eosinophil percentage $(r=0.695, P<0.001)$ and $\Delta$ eosinophil count $(r=0.699$, $P<0.001$ ) (Figure 2).

\section{Relationship of FeNO and clinical state}

The median FeNO levels were 79 (41-88) and 35 (26-49) ppb in uncontrolled (13/74 measurements) and controlled (61/74 measurements) CEP, respectively, showing a significant difference between the clinical states $(P=0.010)$.

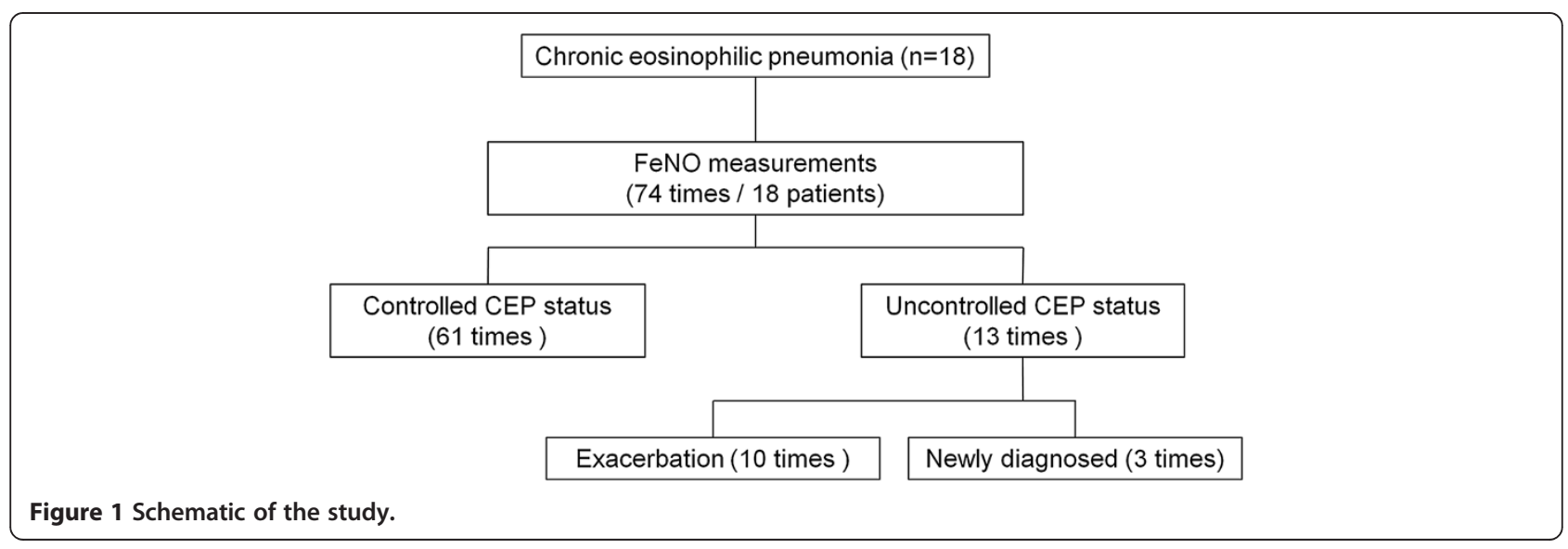




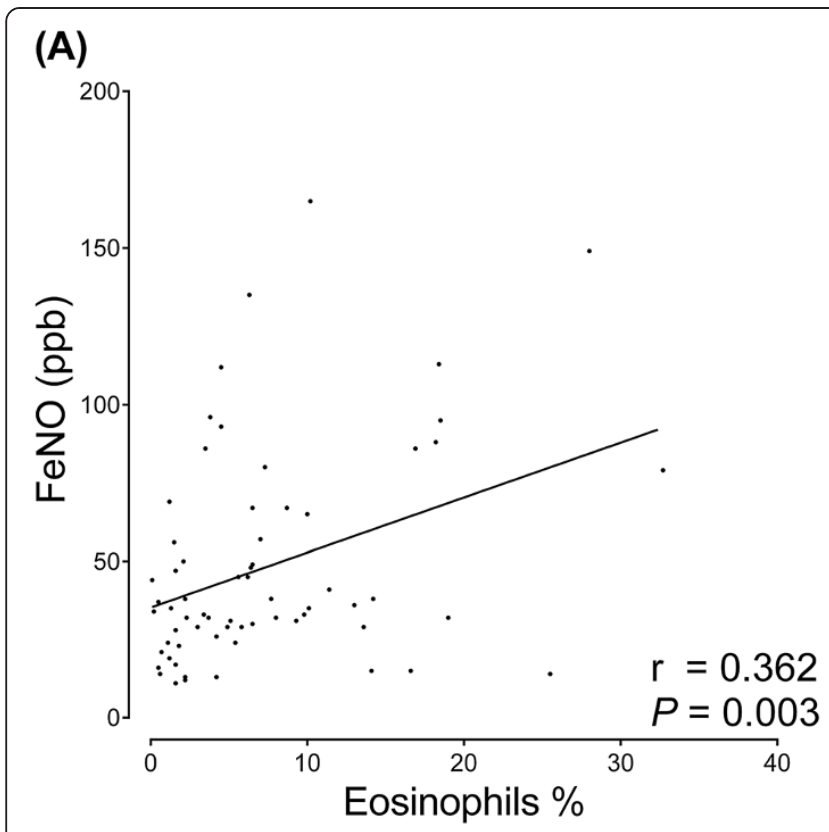

(C)

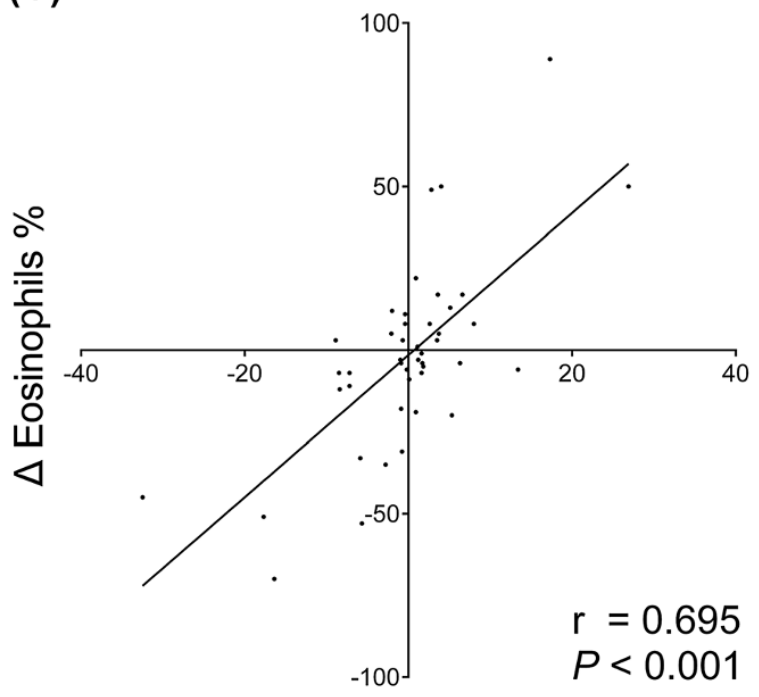

$\triangle \mathrm{FeNo}$
(B)

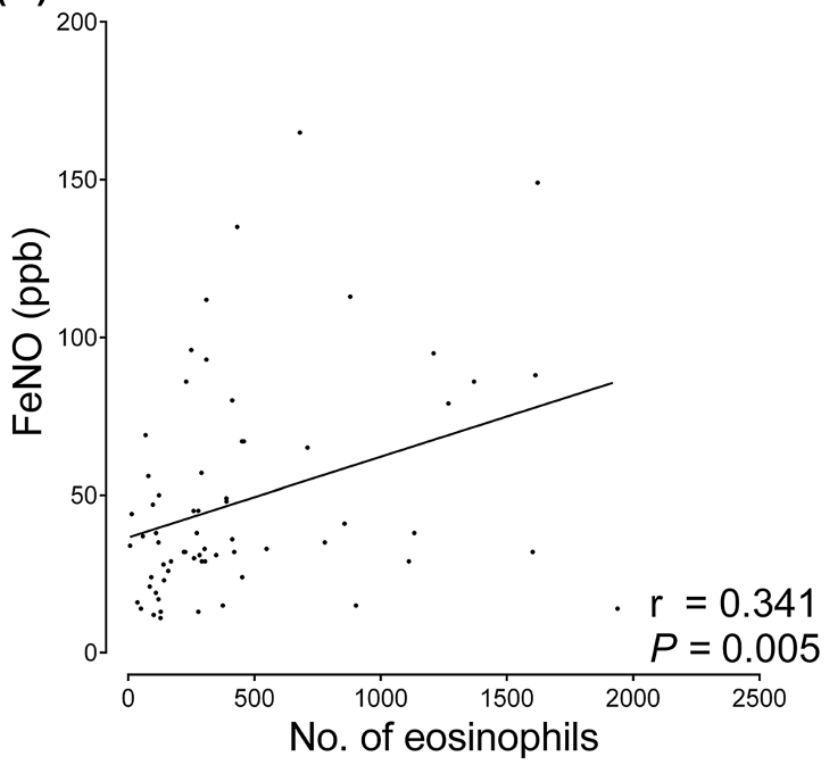

(D)

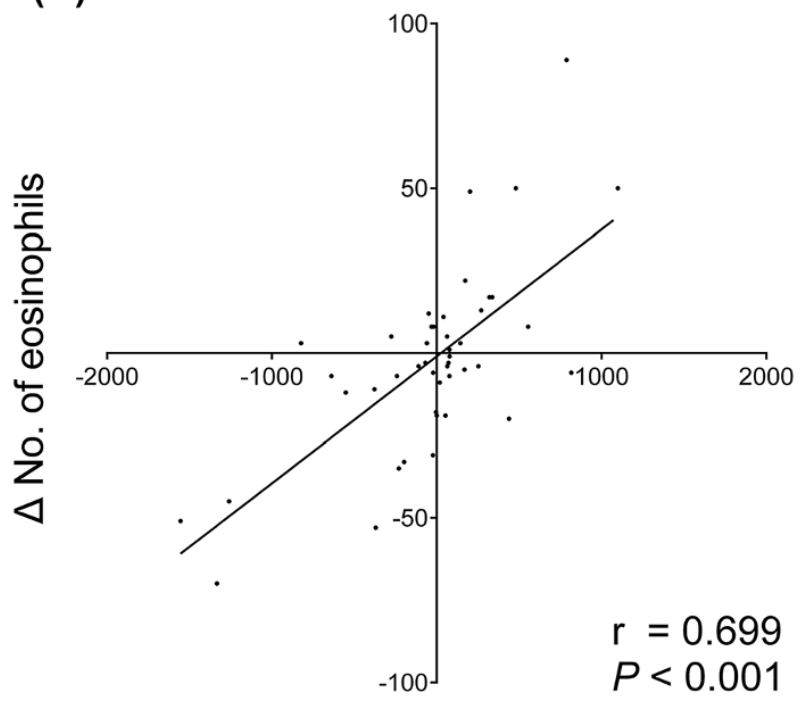

$\triangle \mathrm{FeNo}$

Figure 2 Relationship of FeNO level and peripheral eosinophilia in CEP. Scattergrams of FeNO level against peripheral eosinophil percentage (A) and count (B) as well as $\Delta$ FeNO against $\Delta$ eosinophil percentage (C) and $\Delta$ eosinophil count (D) at every assessment point are shown.

The median peripheral eosinophil percentage was also higher in the uncontrolled state $(17.5 \%$ [10.8-22.3\%] vs. $3.8 \%$ [1.6-6.5\%]; $P<0.001)$. The peripheral eosinophil count showed a similar result (1239 [569-1608] cells $/ \mu \mathrm{L}$ vs. 250 [110-389] cells $/ \mu \mathrm{L} ; P<0.001$ ) (Figure 3 ).

In nine of the 10 exacerbation events, FeNO level was measured after corticosteroid administration. The median FeNO level significantly decreased after the treatment (81 [67-95] ppb vs. 37 [32-44] ppb; $P=0.004]$. In five events, FeNO level was measured both before and after the episode. Significant changes in FeNO level was noted according to the clinical state of CEP $(P=0.022)$ (Figure 4). There is one current smoker. His FeNO was measured after one hour cessation of smoking according to previous recommendation because smoking may decrease FeNO level $[18,19]$. His FeNOs were measured two times in stable state (29 and $33 \mathrm{ppb}$ ) which were within controlled state IQR (26-49). 


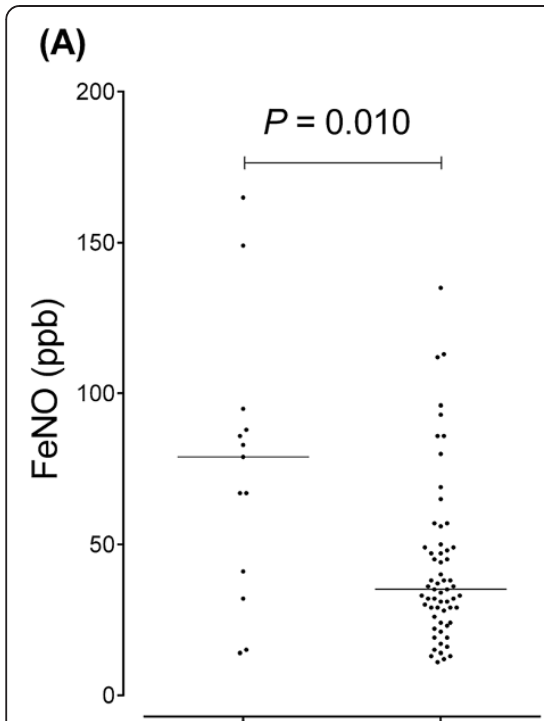

Uncontrolled Controlled
(B)

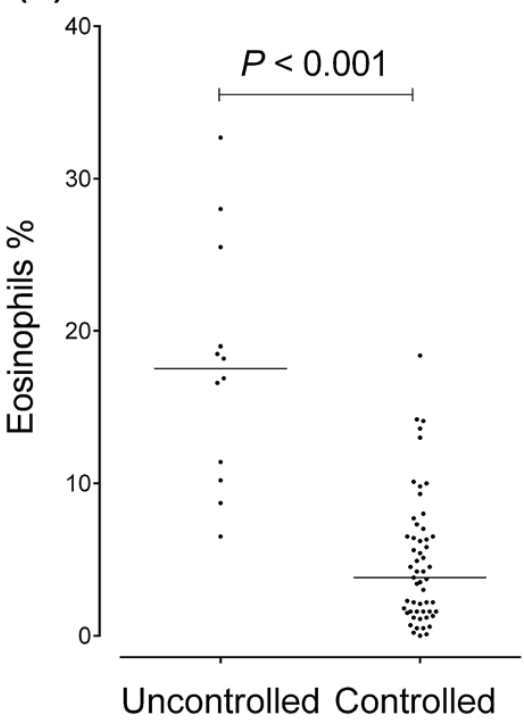

(C)

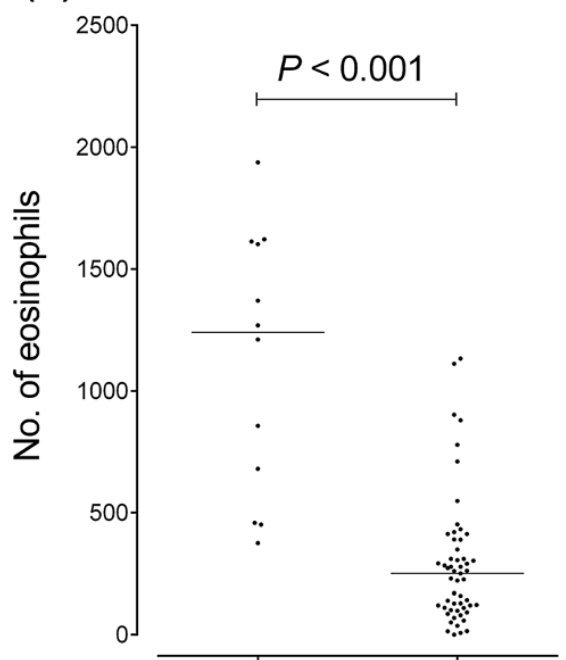

Uncontrolled Controlled

Figure 3 Parametric changes according to the clinical state of CEP. FeNO levels (A), peripheral eosinophil percentages (B), and peripheral eosinophil counts $\mathbf{( C )}$ in the controlled and uncontrolled states of CEP are shown.

\section{Diagnostic accuracy of FeNO}

The area under the curve (AUC) of FeNO level was 0.835 (95\% confidence interval $=0.716-0.954)$. At the cutoff level of $66 \mathrm{ppb}$, the sensitivity and specificity were 0.80 and 0.84 , respectively. Further, the AUC of $\triangle \mathrm{FeNO}$ was 0.918 ; at the cutoff value of $8.4 \mathrm{ppb}$, the sensitivity and specificity were 0.83 and 0.84 , respectively (Figure 5 and Table 2). With regard to the ATS guidelines [20], the sensitivity and specificity at the 50-ppb cutoff level were 0.80 and 0.77 , respectively, and those at the $10-\mathrm{ppb}$ cutoff level of $\triangle \mathrm{FeNO}$ were 0.67 and 0.86 , respectively (Table 2).

The peripheral eosinophil percentage of $8.4 \%$ showed the best sensitivity $(0.89)$ and specificity $(0.79)$ for predicting exacerbation of CEP (AUC =0.906). Further, the peripheral eosinophil count of 451 cells $/ \mu \mathrm{L}$ was the best cutoff value $(\mathrm{AUC}=0.923$; sensitivity $=0.89$; specificity $=0.83$ ) (Figure 5 and Table 2).

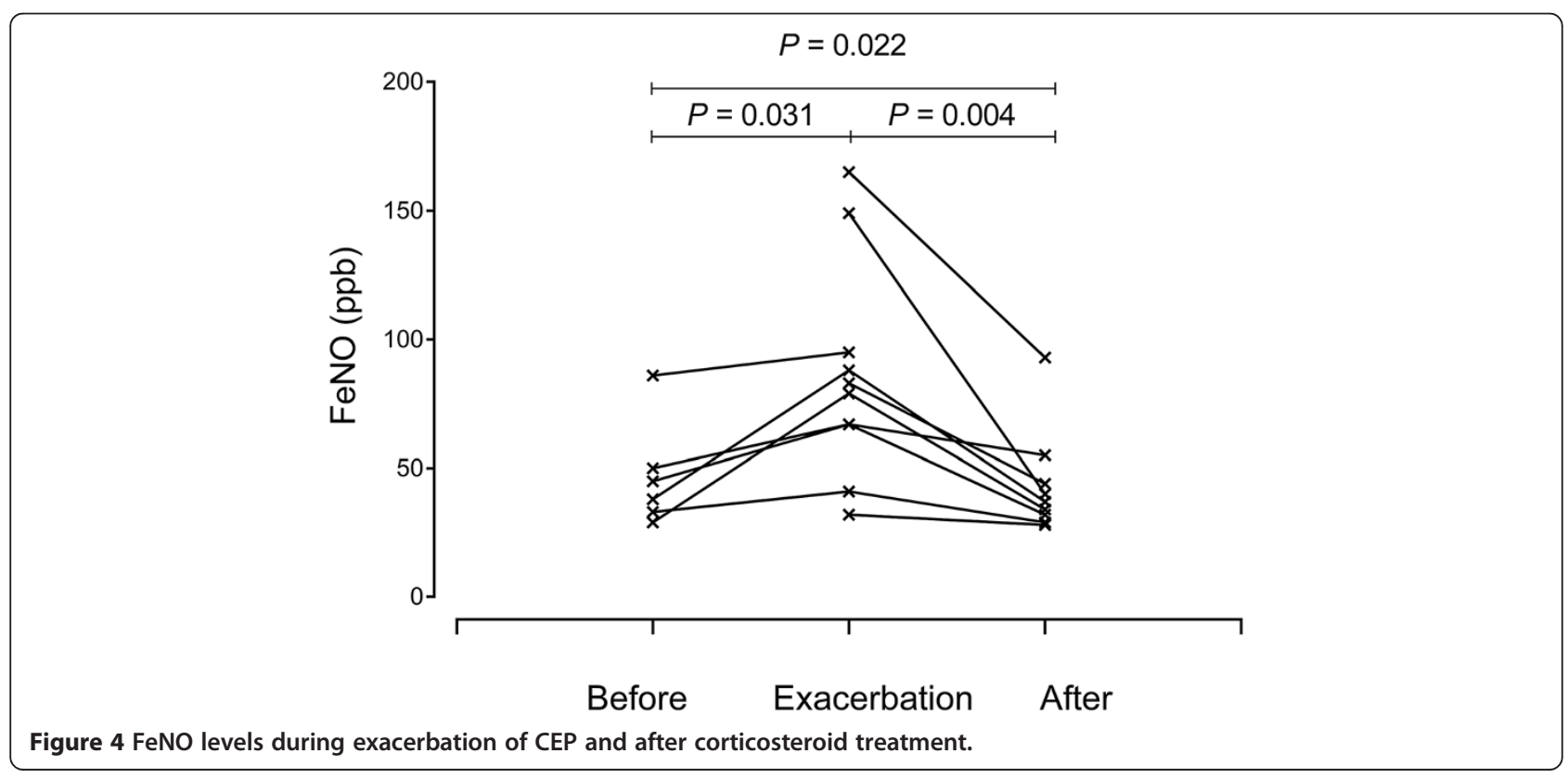




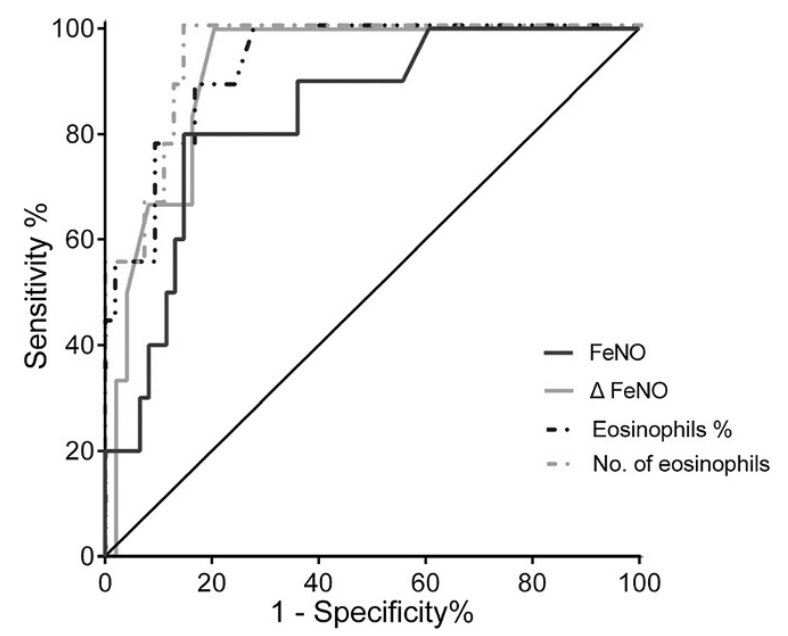

Figure 5 ROC curves of the studied parameters for predicting exacerbation of CEP. ROC curves of FeNO level (black solid line), $\Delta$ FeNO (gray solid line), peripheral eosinophil percentage (black dotted line), and peripheral eosinophil count (gray dashed-dotted line) are shown.

\section{Discussion}

In this study, we evaluated FeNO as a potential marker of eosinophilic parenchymal inflammation and the clinical course of CEP. We found a moderate positive correlation between FeNO level and the degree of peripheral eosinophilia. Uncontrolled CEP was associated with a significantly higher FeNO level, and FeNO level increased during exacerbation events and decreased after corticosteroid treatment. To the best of our knowledge, this is the first study of FeNO in patients with CEP.

There are no clear diagnostic criteria for CEP. Most authors do not recommend histopathologic proof for establishing the diagnosis. Its diagnosis is based on suggestive clinical features, characteristic radiographic appearance, and peripheral eosinophilia [1,3,21]. We applied the Marchand et al. [1] criteria in this study. BAL fluid analysis may be helpful in diagnosis but is not a prerequisite

Table 2 Diagnostic validity of the studied parameters for exacerbation of CEP

\begin{tabular}{lcccc}
\hline Variable & AUC & Cutoff value & Sensitivity & Specificity \\
\hline FeNO level & 0.835 & $66.0 \mathrm{ppb}$ & 0.80 & 0.84 \\
& & $50.0 \mathrm{ppb}^{*}$ & 0.80 & 0.77 \\
$\Delta$ FeNO & 0.918 & $8.4 \mathrm{ppb}$ & 0.83 & 0.84 \\
& & $10.0 \mathrm{ppb}^{* *}$ & 0.67 & 0.86 \\
Peripheral eosinophil & 0.906 & $8.4 \%$ & 0.89 & 0.79 \\
$\begin{array}{l}\text { percentage } \\
\text { Peripheral eosinophil }\end{array}$ & 0.923 & $451 \mathrm{cells} / \mu \mathrm{L}$ & 0.89 & 0.83 \\
count & & & & \\
\hline
\end{tabular}

*FeNO level $>50 \mathrm{ppb}$ is indicative of eosinophilic inflammation and corticosteroid responsiveness in symptomatic patients [20].

${ }^{* *} \Delta \mathrm{FeNO}>10 \mathrm{ppb}$ indicates significant increase in FeNO level [20].
$[9,11]$. The patients who did not undergo BAL not only met the diagnostic criteria but also demonstrated the clinical course of CEP.

CEP seems to show a pattern of waxing and waning frequently. Most patients experience exacerbation events when corticosteroid treatment is discontinued or tapered $[1,2]$. In previous long-term follow-up studies, 59-69\% of the patients were still prescribed oral corticosteroid at the last follow-up visit $[1,2]$. In this study, $72.2 \%(13 / 18)$ used prednisolone at the last assessment point.

Numerous studies have demonstrated the relationships of FeNO with eosinophilic airway inflammation [20] and peripheral eosinophilia $[22,23]$ in asthma. The positive correlation between FeNO level and peripheral eosinophilia in this study suggests that FeNO may reflect eosinophilic inflammation in CEP. Further, FeNO level increases during uncontrolled asthma and decreases during treatment with anti-inflammatory agents $[6,24]$; increase in FeNO level also predicts loss of asthma control [25]. In the present study, FeNO level showed a similar trend.

Peripheral eosinophil counts do not necessarily indicate the extent of eosinophilic involvement in affected tissue [26]. The present results show that FeNO measurement is not inferior to peripheral eosinophil percentage or count for monitoring eosinophilic inflammation in CEP. In some ways, it is more useful because the measurement method is completely noninvasive and easy to apply, and results are obtained immediately [20]. Moreover, the handheld FeNO monitor has the advantage of homebased use [27].

The FeNO level of $66.0 \mathrm{ppb}$ showed the largest AUC with high sensitivity and specificity for predicting exacerbation of CEP. This value is near the ATS-recommended cutoff level ( $>50 \mathrm{ppb})$ [20], which also showed good sensitivity (80\%) and specificity (77\%). To account for each patient's state of eosinophilic inflammation, we also evaluated $\triangle \mathrm{FeNO}$. The change in peripheral eosinophilia correlated well with $\Delta \mathrm{FeNO}$. Furthermore, the $\Delta \mathrm{FeNO}$ value of $8.4 \mathrm{ppb}$ showed good sensitivity and specificity for predicting exacerbation of CEP, similar to the ATSrecommended value of $10 \mathrm{ppb}$ [20].

The present study has several limitations. First, all the FeNO measurements were combined because of the irregular assessment points in the small number of cases. However, the FeNO levels were simultaneously measured with the peripheral eosinophil and clinical parameters. Second, the 1-year follow-up duration is not enough to predict the long-term course of CEP. Third, the clinicians were aware of each patient's FeNO levels, although they did not use them for tailoring the corticosteroid treatment. Fourth, FeNO levels of only three patients were measured at diagnosis of CEP. Additional FeNO data are needed to determine the cutoff value for diagnosis of CEP. 
Fifth, this retrospective study was conducted at a single center. Prospective multicenter clinical trials are required to analyze the association of symptoms, peripheral eosinophilia, and FeNO.

\section{Conclusions}

FeNO may be a useful marker for monitoring eosinophilic parenchymal inflammation and determining the appropriate corticosteroid dose in CEP.

\section{Abbreviations}

AEP: Acute eosinophilic pneumonia; AUC: Area under the curve; BAL: Bronchoalveolar lavage; CEP: Chronic eosinophilic pneumonia; FeNO: Fractional exhaled nitric oxide; IQR: Interquartile range; ppb: Particles per billion; ROC: Receiver operating characteristic.

\section{Competing interests}

The authors declare that they have no competing interests.

\section{Authors' contributions}

JYP developed the study design, measured FeNO levels, analyzed the data, and drafted the manuscript. TL, HYL, YJL, JSP, YJC, HIY, and JHL selected and followed the patients and critically read the paper. CTL conceived the study, developed the study design, collected the data, and drafted and revised the manuscript. All the authors read and approved the final manuscript.

Received: 5 April 2014 Accepted: 6 May 2014

Published: 12 May 2014

\section{References}

1. Marchand E, Reynaud-Gaubert M, Lauque D, Durieu J, Tonnel AB, Cordier JF: Idiopathic chronic eosinophilic pneumonia. A clinical and follow-up study of 62 cases. The Groupe d'Etudes et de Recherche sur les Maladies "Orphelines" Pulmonaires (GERM“O”P). Medicine (Baltimore) 1998 77(5):299-312

2. Naughton M, Fahy J, FitzGerald MX: Chronic eosinophilic pneumonia. A long-term follow-up of 12 patients. Chest 1993, 103(1):162-165.

3. Alam M, Burki NK: Chronic eosinophilic pneumonia: a review. South Med J 2007, 100(1):49-53,

4. Oh MJ, Lee JY, Lee BJ, Choi DC: Exhaled nitric oxide measurement is useful for the exclusion of nonasthmatic eosinophilic bronchitis in patients with chronic cough. Chest 2008, 134(5):990-995.

5. Berlyne GS, Parameswaran K, Kamada D, Efthimiadis A, Hargreave FE: A comparison of exhaled nitric oxide and induced sputum as markers of airway inflammation. J Allergy Clin Immunol 2000, 106(4):638-644.

6. Payne DN, Adcock IM, Wilson NM, Oates T, Scallan M, Bush A: Relationship between exhaled nitric oxide and mucosal eosinophilic inflammation in children with difficult asthma, after treatment with oral prednisolone. Am J Respir Crit Care Med 2001, 164(8 Pt 1):1376-1381.

7. Warke TJ, Fitch PS, Brown V, Taylor R, Lyons JD, Ennis M, Shields MD: Exhaled nitric oxide correlates with airway eosinophils in childhood asthma. Thorax 2002, 57(5):383-387.

8. Knuffman JE, Sorkness CA, Lemanske RF Jr, Mauger DT, Boehmer SJ, Martinez FD, Bacharier LB, Strunk RC, Szefler SJ, Zeiger RS, Taussig LM: Phenotypic predictors of long-term response to inhaled corticosteroid and leukotriene modifier therapies in pediatric asthma. J Allergy Clin Immunol 2009, 123(2):411-416.

9. Smith AD, Cowan JO, Brassett KP, Filsell S, McLachlan C, Monti-Sheehan G, Herbison GP, Taylor DR: Exhaled nitric oxide: a predictor of steroid response. Am J Respir Crit Care Med 2005, 172(4):453-459.

10. Donohue JF, Jain N: Exhaled nitric oxide to predict corticosteroid responsiveness and reduce asthma exacerbation rates. Respir Med 2013, 107(7):943-952

11. Michils A, Baldassarre S, Van Muylem A: Exhaled nitric oxide and asthma control: a longitudinal study in unselected patients. Eur Respir J 2008, 31(3):539-546

12. Petsky HL, Cates CJ, Lasserson TJ, Li AM, Turner C, Kynaston JA, Chang AB: A systematic review and meta-analysis: tailoring asthma treatment on eosinophilic markers (exhaled nitric oxide or sputum eosinophils). Thorax 2012, 67(3):199-208.

13. Smith AD, Cowan JO, Brassett KP, Herbison GP, Taylor DR: Use of exhaled nitric oxide measurements to guide treatment in chronic asthma. N Engl J Med 2005, 352(21):2163-2173.

14. Guo FH, De Raeve HR, Rice TW, Stuehr DJ, Thunnissen FB, Erzurum SC Continuous nitric oxide synthesis by inducible nitric oxide synthase in normal human airway epithelium in vivo. Proc Natl Acad Sci U S A 1995, 92(17):7809-7813.

15. Lee JE, Rhee CK, Lim JH, Lee SM, Shim YS, Lee CT, Lee SW: Fraction of exhaled nitric oxide in patients with acute eosinophilic pneumonia. Chest 2012, 141(5):1267-1272.

16. Cho YJ, Lim HJ, Park JS, Lee JH, Lee CT, Yoon HI: Measurement of fractional exhaled nitric oxide in stable bronchiectasis. Tuberc Respir Dis 2013, 74(1):7-14.

17. American Thoracic Society, European Respiratory Society: ATS/ERS recommendations for standardized procedures for the online and offline measurement of exhaled lower respiratory nitric oxide and nasal nitric oxide, 2005. Am J Respir Crit Care Med 2005, 171(8):912-930.

18. Travers J, Marsh S, Aldington S, Williams M, Shirtcliffe P, Pritchard A, Weatherall M, Beasley R: Reference ranges for exhaled nitric oxide derived from a random community survey of adults. Am J Respir Crit Care Med 2007, 176(3):238-242.

19. Sandrini A, Taylor DR, Thomas PS, Yates DH: Fractional exhaled nitric oxide in asthma: an update. Respirology 2010, 15(1):57-70.

20. Dweik RA, Boggs PB, Erzurum SC, Irvin CG, Leigh MW, Lundberg JO, Olin AC, Plummer AL, Taylor DR: An official ATS clinical practice guideline: interpretation of exhaled nitric oxide levels (FENO) for clinical applications. Am J Respir Crit Care Med 2011, 184(5):602-615.

21. Durieu J, Wallaert B, Tonnel AB: Long-term follow-up of pulmonary function in chronic eosinophilic pneumonia. Groupe d'Etude en Pathologie Interstitielle de la Societe de Pathologie Thoracique du Nord. Eur Respir J 1997, 10(2):286-291.

22. Barreto M, Villa MP, Monti F, Bohmerova Z, Martella S, Montesano M, Darder MT, Ronchetti R: Additive effect of eosinophilia and atopy on exhaled nitric oxide levels in children with or without a history of respiratory symptoms. Pediatr Allergy Immunol 2005, 16(1):52-58.

23. Strunk RC, Szefler SJ, Phillips BR, Zeiger RS, Chinchilli VM, Larsen G, Hodgdon K, Morgan W, Sorkness CA, Lemanske RF Jr: Relationship of exhaled nitric oxide to clinical and inflammatory markers of persistent asthma in children. J Allergy Clin Immunol 2003, 112(5):883-892.

24. Fitzpatrick AM, Gaston BM, Erzurum SC, Teague WG: Features of severe asthma in school-age children: Atopy and increased exhaled nitric oxide. J Allergy Clin Immunol 2006, 118(6):1218-1225.

25. Jones SL, Kittelson J, Cowan JO, Flannery EM, Hancox RJ, McLachlan CR, Taylor DR: The predictive value of exhaled nitric oxide measurements in assessing changes in asthma control. Am J Respir Crit Care Med 2001, 164(5):738-743.

26. Szefler SJ, Wenzel S, Brown R, Erzurum SC, Fahy JV, Hamilton RG, Hunt JF, Kita H, Liu AH, Panettieri RA Jr, Schleimer RP, Minnicozzi M: Asthma outcomes: biomarkers. J Allergy Clin Immunol 2012, 129(3 Suppl):S9-S23.

27. Kapande KM, McConaghy LA, Douglas I, McKenna S, Hughes JL, McCance DR, Ennis M, Shields MD: Comparative repeatability of two handheld fractional exhaled nitric oxide monitors. Pediatr Pulmonol 2012, $47(6): 546-550$.

doi:10.1186/1471-2466-14-81

Cite this article as: Park et al: Significance of fractional exhaled nitric oxide in chronic eosinophilic pneumonia: a retrospective cohort study. BMC Pulmonary Medicine 2014 14:81. 